\title{
Research on Relationship Awareness and Motivational Value System Based on Strengths Deployment Inventory (SDI)
}

\author{
Yunli Guo \\ Institute of Finance and Economics, Xinyang Agriculture and Forestry University, Henan, China.
}

Keywords: Leadership, SDI, Influence, Management.

\begin{abstract}
Leadership has been described as the process of social influence in which one person can enlist the aid and support of others in the accomplishment of a common task (Lussier \& Achua, 2010). Different people require different styles of leadership. There are many traits that help people increase the effectiveness of their leadership. In order to have an effective leadership, it is important to build your own leadership style which can expend strengths and avoid weaknesses. Leaders should work hard to develop respect for each member of the team and try to makes team members feel important. Mutual respect is vital to success. Sometimes, rewards and motivation are necessary. Moreover, sometimes it is good for employees to share their opinions and help to get to a solution. Sometimes, it's also important to be able to switch from one leadership style to the others. All of this really can improve people's morale and gain work efficiency.
\end{abstract}

\section{Introduction}

Leadership is the "influencing" process of leaders and followers to achieve organizational objectives through change. Moreover, influencing is the process of affecting others' attitudes and behavior in order to achieve an objective (Lussier \& Achua, 2010). In any business, there is a great need for better leaders. If people want to be successful, it is necessary to develop their leadership skills. All of the self assessments I did also help me realize my leadership traits and skills, so I can improve my strength and develop my weakness. According to the results of my self assessment, I found that I have a greater leadership potential. This result made me excited because it indicates that I have the potential of being a leader. Moreover, understanding people's personalities is important because personality affects behavior as well as perceptions and attitudes. In daily lives, I do always concern about others' feeling and can get along well with them. For example, I can listen to others well and read people's moods accurately, so usually I understand others' needs and feelings. I always believe "on time" and "honesty" is the bases of getting along with people. When I say I will do something, it's done well and on time. Therefore, people will trust you and do business with you when they found you are dependable. According to all of these traits, I believe my leadership style is more democratic. Leaders with such leadership style often encourage participation in decisions, work with employees to determine what to do, and does not closely supervise them.

\begin{tabular}{||c|c|c|c||}
\hline & Blue & Red & Green \\
\hline SDI Blue edition scores & & & \\
\hline When things are going well & 25 & 40 & 35 \\
\hline When things are going wrong & 19 & 39 & 42 \\
\hline SDI Red edition scores & & & \\
\hline When things are going well & 27 & 35 & 38 \\
\hline When things are going wrong & 35 & 26 & 39 \\
\hline
\end{tabular}

\section{Leadership Motivation}

Leadership style is the combination of traits, skills and behaviors leaders use as they interact with followers. Relationships between leaders and followers are based on the leaders' traits and attitudes (Lussier \& Achua, 2010). Due to my democratic leadership style, I concern more about people than 
tasks. It suggests my tendency is to focus on meeting people's needs rather than getting the job done. Therefore, my leadership style is better to apply for content motivation a theory which is focusing on explaining and predicting behavior based on people's needs. All people have the need for achievement, power and affiliation, but to varying degrees. Therefore, it is important to know employees' needs and wants for leaders. There is one practical example which can explain why this applies to my leadership style. When I have team project needed to finish with my peers, I always ask my team members which part they want to do and which areas they are good at. I really want make everyone feel comfortable, so they can do their best for our team project. In addition, once someone finished their parts of project, encouragement and positive feedback are necessary because people can be moved by this kind of motivation and have more energy for their jobs. Moreover, the need of success on the project is the motivation that creating my leadership style. All of us want the success of our team project, so I will do my best to lead my team and get the project done as best as I can. Therefore, our common goal and need are what I want to achieve.

\section{Leadership Strength}

According to all the self assessment I did, I realized some general strengths of mine that can make me become a successful leader. Firstly, integrity is my strength. Integrity refers to behavior that is honest and ethical, making a person trustworthy. I respect promise and when I say I will do something, it's done well and on time. If followers find out their leaders has been dishonest or in some way manipulated them for personal gain, the leader will lose the followers' trust. Therefore, I believe integrity is a necessary trait of a successful leader. Secondly, self-control is also my strength. I think these traits were formed by my family when I was a child because my parents were busy at their business at that time and they did not have enough time to supervise my study and life. They just told me that it was important to practice my self-control ability and this could benefit my whole life. As a result, I need to make plans by myself and finish things depending on the plans. At the beginning, it was hard for me to control myself, so I did not complete my assessments on time and I got teachers' criticism and punishments. Later, I began to force myself to obey the plan and gradually I was used to controlling my life and work everything as planned. I really appreciate my self-control ability and it really benefits both my life and study. Thirdly, I have high energy. Leaders have high energy with a positive drive to work hard to achieve goals. In order to achieve my goal I know I have to pay more than other people. So I always have the high energy on doing things. I always believe in an old saying that is "Constant dropping wears away a stone."

\section{Self-Deployment Inventory (Blue)}

\subsection{When Things are Going Well}

There are four important types of motivation value systems in SDI. They are classified as Altruistic-nurturing, Analytic0autonomizing, Assertive-directing and flexible-cohering. According to the result I got, I find out that I am an assertive-directing person. This kind of motivation value system means that I concern for task accomplishment and organization of people, time, money and any other resources to achieve desired results. In my opinion, the major description of this motivation value system fits me. Like the example I mentioned above, in order to lead my team and get the project done as best as I can, I try to care about team members' feelings and needs and give them necessary encouragements. All of these actions can improve their morale, so they can do their best for this project. Therefore, this can boost task accomplishments.

\subsection{When Things are in Conflict}

In the assessment of things are going well, I got 19 point on blue, 39 on red, and 42 on green. The results falls under the [GR]-B sequences. It means that I am a person who first tries the analytic, logical and reserved response to conflict followed by an assertive, forceful attack based on logic and strategies. If these approaches do not work, I then give in for the sake of harmony but only as a last resort (Elias, page 10). These descriptions fit my style of facing conflicts. Here is a practical example of how would I deal with a conflict. One day I went shopping with my friends. All of us wanted to 
buy a facial cream, so we walked to a counter filled with different cosmetic. When we decided to buy the facial cream we wanted, the salesclerk said that she would give us $10 \%$ discount if we bought another their product. Therefore, we need to think about this option. My friends said it was better to choose her option because we could get discount. However, I thought this was a kind of promotion, so I told them that we could get $10 \%$ discount, but we also need pay more for her this time. In addition, we just need a facial cream and it is stupid to find another unnecessary product, so I decided to only buy the cream I need. However, my friends still insisted on their opinions and claimed that discount was attractive and this could help them save money. Finally, I gave up and end this conversation. This example is exactly match as what the [GR]-B described in SDI inventory paper (Elias, page 10). When I indirectly meet the conflict, I will use my mind to figure out a strategy. If it does not work, I will finally give up.

\section{Self-Deployment Inventory (Red)}

The overall result from my feedback is very different with my own result. Both of when things going well and wrong, the feedback indicates I am a person with flexible-cohering motivational value system, which means I am a friendly person who cares about others, being open mind, and ready for accepting new ideas. Sociable and changeable are the words that describing the Hub system which I will never apply to myself. Indeed, I think both of these assessments are correct. The different results I get from the Blue paper fit the real me. The differences between things are going right or wrong exactly describe how I deal with different situations. However, it could be different between what you think and what you want to be seen. Whatever who I am, I would like to be seen by others as a flexible person who is not too push or too slowdown, friendly and open mind, no matter what kind of situation I am involved with. The reason is understandable, so the result of the blue and red forms clearly shows my mind.

\section{Leadership Map}

\subsection{Future Endeavors}

Confidence and enthusiasm are the essential and effective leadership traits, which make a great leader. A good leader should always boost the morale of his workforce, so leaders should have tremendous energy and enthusiasm to work for long hours and achieve the set targets. The effective leadership traits include generating a team spirit among the workforce by proper implementation of strategies (Lussier \& Achua, 2010). Self confidence is important to anyone's success in business and in life. In many ways, self confidence can be described as self respect and enjoyment of life's challenges. I also know that self confident people are more successful in everything they do than those who lack confidence. Therefore, I believe my self confidence can help me being a leader. Moreover, I am a person who likes thinking. When facing some complex situations, I can stay calm and think about many factors that impact upon the complex situations. Therefore, all of my friends say that I am a rational person because I can explain these interactions in terms others can understand. I remembered that one of my friends used to ask for my advices and analysis when she faced some complex situation, because she could not think anything when facing difficulties. In fact, when I explained complex events to her in an understandable way, I felt confident because this made me realize my value that I can help others. However, self-confidence and analytical skill are not enough for being a successful leader. In order to be a successful leader, all of the leadership skills are necessary, so I should pay attention to these competencies and do my best to possess more leadership traits.

\section{Assessment Evaluation}

I believe that the SDI form is really a good tool for me to understand my strengths and weakness of leadership skills. It also teaches me how to apply these traits in my real life. By doing these self assessments from the textbook, it clarifies my strengths and weaknesses on specific points. Therefore, 
these self assessments help me realize the traits of leadership by organizing the answers of situational questions. SDI is a self-scoring instrument which measures an individual's Motivational Value System. Whereas many other tools measure behavior, the SDI goes beyond behavior into the motivations and values that underlie those behaviors. It explores a person's motivational values both when things are going well, and when the person faces conflict or opposition. It combines the answers into a figure and we can clearly describe ourselves depending on this figure because every color and dots are provided through our answers. Moreover, the overall scores and result are meaningful and particular for the participators. In addition, another special part of SDI is that the red form asks the opinions from other for the similar questions. This can make the results more accurate and comprehensive. In conclusion, both the text book assessments and SDI on my leadership knowledge can be described as professional, knowledgeable and valuable.

\section{References}

[1]. Robert N. Lussier and Christopher F. Achua (2010), Leadership: Theory, Application, \& Skill Development 4e. Thomson South western.

[2]. Elias H. Porter, Ph.D. SDI Standard Edition, Personal Strengths Publishing

[3]. Davis, Derek H. "The Evolution of Religious Liberty as a Universal Human Right". Retrieved on June 24, 2012, from http://www.religiousfreedom.com/wrpt/Chinarpt.htm.

[4]. J. Macionis, Society: The basics, 9th edition.2007, Pearson.

[5]. Texas Instruments (2009), Ethic Overview. Retrieved September 23, 2012, from http://en.wikipedia.org/wiki/Texas_Instruments

[6]. Harbert \& Ingulli (2009). Law \& Ethics in the Business Environment. 6th Ed. South-Western Cengage Published.

[7]. Lopatto, E. (2008). Reasonable Belief. Retrieved on November 14, 2012 from http://jneedlel.home.mindspring.com/reasbel.htm. 